\title{
Biblioterapia: das dissertações e teses aos cursos de Bibliotecono- mia no Brasil
}

\section{Bibliotherapy: From dissertations and theses to the courses of Librarianship in Brazil}

\author{
Mariza Inês da Silva Pinheiro \\ Doutora em Documentação \\ Universidade Federal do Mato Grosso \\ mariza.ines@terra.com.br \\ Daniela Duarte Ramires \\ Graduada em Biblioteconomia \\ Universidade Federal do Rio Grande \\ danieladramires@yahoo.com
}

\section{Resumo}

O estudo objetiva identificar na literatura científica brasileira (teses e dissertações), os enfoques dados à biblioterapia, sob o viés da Biblioteconomia e da Ciência da Informação e também verificar a existência da disciplina Biblioterapia nos cursos de Biblioteconomia do Brasil. A pesquisa ocorreu entre setembro a novembro de 2018, em dois momentos: primeiro momento foi analisado os documentos (teses e dissertações) recuperados na busca da base de dados BDTD/IBICT com o tema biblioterapia, em segundo momento, realizou-se um levantamento sobre as 36 universidades brasileiras que possuem o curso de Biblioteconomia e entre essas quantas oferecem a disciplina de biblioterapia como opção nos Quadros de Sequência Lógica (QSL) dos cursos. Foram encontradas entre teses e dissertações 14 itens em diversas áreas do conhecimento, sendo assim optou-se em analisar os sete documentos no qual as áreas abrangentes são: Biblioteconomia, Ciência da Informação e Gestão da Informação. Observou-se que não existe uma única área de conhecimento responsável pela biblioterapia, pois a mesma trata-se de uma atividade multidisciplinar. Constatou-se que somente uma universidade disponibiliza a disciplina de biblioterapia como uma opção de agregar conhecimentos aos discentes interessados nesse campo de atuação.

\section{Palavras-chave}

Biblioterapia. Bibliotecário. Cursos de Bacharel em Biblioteconomia.

\begin{abstract}
The study aims to identify in the Brazilian scientific literature, more specifically the theses and dissertations, the approaches given to bibliotherapy, under the bias of Library and Information Science and also to verify the existence of the discipline of Bibliotherapy in the courses of Library Science in Brazil. The research took place between September and November 2018, in two moments: firstly, the documents (theses and dissertations) retrieved in the search for the BDTD / IBICT database with the topic of bibliotherapy were analyzed, secondly a survey was carried out on the 36 Brazilian universities that have the Librarianship course and among these many offer the discipline of bibliotherapy as an option in the QSL of the courses. Theses and dissertations were found among 14 items in several areas of knowledge, so it was decided to analyze the seven documents in which the broad areas are: Librarianship, Information Science and Information Management. It was observed that there is no single area of knowledge responsible for bibliotherapy, since it is a multidisciplinary activity. It was verified that only one university offers the discipline of bibliotherapy as an option to add knowledge to the students interested in this field.
\end{abstract}

\section{Keywords}

Biblioterapy. Librarian. Bachelor's Degree in Library Science. 


\section{INTRODUÇÃO}

A leitura sempre foi e será um meio de ampliar o nível de conhecimento intelectual e cultural. Um leitor assíduo possui maior facilidade de se expressar, seja por meio da escrita ou uma linguagem oral. Além de seus inúmeros benefícios, o ato de ler, torna-se um momento mágico no qual o leitor conhece novas línguas, lugares e culturas diversas, sem precisar sair do seu lugar de origem. A leitura pode ser considerada como uma opção terapêutica transformando momentos de tristeza, angústia ou sensações que limitam o indivíduo a crescer pessoalmente ou profissionalmente em situações mais serenas. Sendo assim, a leitura pode ser um aliado para amenizar esses sentimentos e frustrações.

Ler pode ser considerado uma terapia, neste sentido, incentivar e trabalhar o gosto pela leitura pode resultar numa função terapêutica alternativa e, consequentemente, amenizar alguns problemas emocionais. Assim, nesta linha de pensamento, a biblioterapia possui uma característica de mediar uma comunicação entre o real e o imaginário, trata-se de um processo multidisciplinar, não existe apenas um responsável por esse método, diversos profissionais desde que qualificados podem contribuir interagindo durante o processo terapêutico (CALDIN, 2001, 2009).

Inicialmente esse tema surgiu ao ler duas publicações de Caldin de 2001 (artigo da Revista Enc. Bibli) e de 2009 (Tese de doutorado), na qual menciona o bibliotecário como mediador da informação e um possível facilitador (colaborador) para a realização dessa atividade. A escolha do livro ou história a ser utilizada pelo mediador/facilitador é um dos momentos mais delicados da biblioterapia, ou seja, saber antes o perfil dos participantes e, assim, apresentar (livro ou história) conforme a realidade diagnosticada.

A biblioterapia teve um enfoque sobre o olhar da Biblioteconomia e de outras áreas do conhecimento. Desta forma, foi possível identificar por meio da literatura científica, as iniciativas que os pesquisadores mencionam como fatores importantes no processo terapêutico da aplicabilidade da Biblioterapia.

A literatura científica descreve a biblioterapia como uma atividade multidisciplinar, permitindo que o bibliotecário faça parte desse rol de profissionais para desenvolver projetos que utilizam a leitura como uma alternativa terapêutica.

A biblioterapia inicialmente era utilizada para pessoas hospitalizadas e também com algum tipo de distúrbio mental. Atualmente ela abrange um campo maior podendo ser aplicada em asilos, escolas, creches, prisões, entre outros lugares. Pois uma de suas metas é proporcionar momentos de descontração e prazer, transmitindo segurança para o ouvinte, assim permitindo que ele se sinta parte da história narrada absorvendo as coisas boas e deixando de lado seus medos, tristezas, sofrimentos e angustias, entre outras sensações, seja ela de caráter moral, social, física ou mental.

Assim, surgiu a necessidade de analisar as teses e dissertações que apresentam estudos sobre a área da biblioterapia, identificando suas contribuições ao decorrer dessas atividades, pois é mais um campo de atuação, no qual, o profissional bibliotecário pode ser inserido. Caldin (2009) em sua tese corrobora com a ideia de que a biblioterapia divide-se em duas partes, sendo elas: biblioterapia de desenvolvimento, na qual uma possível área atuante é a Biblioteconomia e a biblioterapia clínica, na qual os profissionais atuantes pertencem a Psicologia.

Ao decorrer desse trabalho serão explorados os conceitos básicos da biblioterapia, seus métodos de aplicação e as categorias na qual a mesma é dividida. 
Esta pesquisa visa beneficiar aos bibliotecários, pedagogos, psicólogos e a todos os pesquisadores, profissionais atuantes nesta área e interessados por esse tema. E também para futuras pesquisas, na qual terão um panorama das bibliografias publicadas sobre o assunto em questão e quais os cursos de Biblioteconomia e Ciência da Informação estão ofertando as disciplinas de biblioterapia nos Quadros de Sequência Lógica (QSL) como forma de complementação para o estudante.

A coleta de dados das teses e dissertações foi importante para composição da pesquisa, na qual um dos objetivos era identificar na literatura científica brasileira os enfoques dados à biblioterapia, sob o viés da Biblioteconomia e da Ciência da Informação nas teses e dissertações. Assinala-se ainda, que estas fontes de informações são fundamentais para adquirir conhecimentos.

\section{BIBLIOTERAPIA E ALGUNS CONCEITOS}

De acordo com as bibliografias pesquisadas, a biblioterapia é uma atividade na qual utiliza a leitura como auxílio no tratamento de pessoas com problemas físico, mental, social, emocional, educacional, sem distinção de faixa etária. Podendo ser aplicada em escolas, creches, asilos, hospitais, presídios, orfanatos, entre outros locais. Um dos objetivos da biblioterapia é proporcionar momentos de descontração e lazer, criando um vinculo/diálogo entre leitor e ouvinte, fazendo com que estes se sintam parte da história. Caldin (2001) relata que a biblioterapia não se trata apenas de uma leitura simples, mas sim de uma leitura dirigida, uma troca de experiências, uma discussão em grupo, na qual o indivíduo aprende a lidar com seus medos e frustrações.

Diz ainda Caldin (2001, p.36) que "A biblioterapia contempla não apenas a leitura, mas também o comentário que lhe é adicional. [...] em uma imbricação que conduz à reflexão, ao encontro das múltiplas verdades, em que o curar se configura como o abrir-se a uma outra dimensão."

De acordo com Ferreira (2003, p.39) a "Biblioterapia é uma técnica de mudança de comportamento através do autoconhecimento e que utiliza as qualidades racionais (intelecto, inteligência, compreensão cognitiva) e emotivas dos indivíduos que se submetem a ela, para obter uma modificação do seu comportamento". Para Valencia e Magalhães $(2015$, p. 10) "a biblioterapia é considerada também uma técnica que utiliza qualquer tipo de material bibliográfico, em que a leitura e outras atividades lúdicas, sobre variados temas, auxiliam as pessoas a lidarem com os seus problemas emocionais, sociais e físicos".

Os autores corroboram com a ideia de que a biblioterapia trata-se de uma técnica, que visa a mudança de comportamento do indivíduo por meio dos materiais bibliográficos e sua aplicação de forma apropriada.

Segundo Silva (2017, p. 6), a "Biblioterapia é compreendida como um campo interdisciplinar e tem suporte em diferentes áreas, tais como a Biblioteconomia, Literatura, Psicologia e Filosofia".

Neste aspecto, Silva (2005) identificou em suas pesquisas que a Psicologia e Biblioteconomia são as áreas de conhecimento mais destacadas nas fontes documentais realizadas.

O conceito de biblioterapia varia muito dentro do campo científico, para melhor entendimento esses conceitos são apresentados no quadro 1, a seguir, alguns autores e sua visão sobre o que é biblioterapia e seus objetivos. 
Quadro 1 - Conceitos e objetivos de Biblioterapia

\begin{tabular}{|c|c|c|}
\hline Autor & Conceito & Objetivo \\
\hline Alice Bryan & $\begin{array}{l}\text { É a prescrição de materiais de leitura } \\
\text { que auxiliem a desenvolver maturi- } \\
\text { dade e nutram e mantenham a saú- } \\
\text { de mental. }\end{array}$ & $\begin{array}{l}\text { Permitir ao leitor verificar que há mais de uma solução } \\
\text { para seu problema; auxiliar o leitor a pensar na expe- } \\
\text { riência vicária em termos humanos e não materiais; } \\
\text { proporcionar informações necessárias para a solução } \\
\text { dos problemas, e, encorajar o leitor a encarar sua } \\
\text { situação de forma realista de forma a conduzir à ação. }\end{array}$ \\
\hline $\begin{array}{c}\text { L. H. } \\
\text { Twelfortf }\end{array}$ & $\begin{array}{l}\text { É um método subsidiário da psicote- } \\
\text { rapia; um auxílio no tratamento que } \\
\text { através da leitura, busca a aquisição } \\
\text { de um conhecimento melhor de si } \\
\text { mesmo e das reações dos outros, } \\
\text { resultando em um melhor ajusta- } \\
\text { mento à vida. }\end{array}$ & $\begin{array}{l}\text { Fazer a introspecção para o crescimento emocional; } \\
\text { melhorar o entendimento das emoções; verbalizar e } \\
\text { exteriorizar os problemas; ver objetivamente os pro- } \\
\text { blemas, afastar a sensação de isolamento; verificar } \\
\text { falhas alheias semelhantes às suas; aferir valores; } \\
\text { realizar movimentos criativos e estimular novos inte- } \\
\text { resses. }\end{array}$ \\
\hline $\begin{array}{l}\text { Kenneth } \\
\text { Appel. }\end{array}$ & $\begin{array}{l}\text { É o uso de livros, artigos e panfletos } \\
\text { como coadjuvantes no tratamento } \\
\text { psiquiátrico. }\end{array}$ & $\begin{array}{l}\text { Adquirir informação sobre a psicologia e a fisiologia do } \\
\text { comportamento humano; capacitar o indivíduo a se } \\
\text { conhecer melhor; criar interesse em algo exterior ao } \\
\text { indivíduo; proporcionar a familiarização com a reali- } \\
\text { dade externa; provocar a liberação dos processos } \\
\text { inconscientes; oferecer a oportunidade de identifica- } \\
\text { ção e compensação; clarificar as dificuldades individu- } \\
\text { ais; realizar as experiências do outro para obter a cura } \\
\text { e auxiliar o indivíduo a viver mais efetivamente. }\end{array}$ \\
\hline $\begin{array}{l}\text { Louise Rosen- } \\
\text { blatt }\end{array}$ & $\begin{array}{l}\text { É uma ajuda para o ajustamento } \\
\text { social e pessoal; a literatura imagina- } \\
\text { tiva é útil para ajustar o indivíduo } \\
\text { tanto em relação aos seus conflitos } \\
\text { íntimos como em conflitos com ou- } \\
\text { tros. Como o pensamento e senti- } \\
\text { mento estão interligados, o processo } \\
\text { de pensamento reflexivo estimulado } \\
\text { pela leitura é um prelúdio para a } \\
\text { ação. }\end{array}$ & $\begin{array}{l}\text { Divide os objetivos em de cura e de prevenção. Obje- } \\
\text { tivos de cura: aumentar a sensibilidade social; ajudar o } \\
\text { indivíduo a se libertar dos medos e das obsessões de } \\
\text { culpa; proporcionar a sublimação por meio da catarse, } \\
\text { e, levar o ser humano a um entendimento de suas } \\
\text { reações emocionais. Objetivos de prevenção: prevenir } \\
\text { o crescimento de tendências neuróticas e, conduzir a } \\
\text { uma melhor administração dos conflitos. }\end{array}$ \\
\hline Orsini & $\begin{array}{l}\text { É uma técnica que pode ser utilizada } \\
\text { para fins de diagnóstico, tratamento } \\
\text { e prevenção de moléstias e de pro- } \\
\text { blemas pessoais. Classifica os objeti- } \\
\text { vos como sendo de: nível intelectual, } \\
\text { nível social, nível emocional e nível } \\
\text { comportamental. }\end{array}$ & $\begin{array}{l}\text { Assim, a biblioterapia tem como objetivos: auxiliar o } \\
\text { autoconhecimento pela reflexão, reforçar padrões } \\
\text { sociais desejáveis, proporcionar desenvolvimento } \\
\text { emocional pelas experiências vicárias e auxiliar na } \\
\text { mudança de comportamento. }\end{array}$ \\
\hline $\begin{array}{l}\text { Mattews e } \\
\text { Lonsdale }\end{array}$ & $\begin{array}{l}\text { Constitui-se em uma terapia de lei- } \\
\text { tura imaginativa, que compreende a } \\
\text { identificação com uma personagem, } \\
\text { a projeção, a introspecção e a catar- } \\
\text { se. }\end{array}$ & $\begin{array}{l}\text { Distinguiram três tipos a terapia de leitura: a de cres- } \\
\text { cimento, a factual e a imaginativa. Assim, os objetivos } \\
\text { são: divertir e educar (crescimento), informar e prepa- } \\
\text { rar o paciente para o tratamento hospitalar (factual) } \\
\text { explorar os sentimentos e tratar os problemas emoci- } \\
\text { onais (imaginativa). }\end{array}$ \\
\hline Caldin & $\begin{array}{l}\text { É a leitura dirigida e discussão em } \\
\text { grupo, que favorece a interação } \\
\text { entre as pessoas, levando-as a ex- } \\
\text { pressarem seus sentimentos: os } \\
\text { receios, as angústias e os anseios. }\end{array}$ & $\begin{array}{l}\text { Proporcionar uma forma de as crianças comunicarem- } \\
\text { se, de perderem a timidez, de exporem seus proble- } \\
\text { mas emocionais e quiçá físicos; oferecer moderação } \\
\text { das emoções às crianças. }\end{array}$ \\
\hline
\end{tabular}

Fonte: Rosa (2006, p. 17-19). 
Cada autor descreve uma definição do que é biblioterapia, mas todas as definições estão de certa forma interligada, pois seu foco principal é a otimização do poder terapêutico que a leitura/livro possui. Neste contexto, Caldin (2001) corrobora com a ideia de que essa aproximação entre o livro e o leitor permite que o indivíduo descubra outro mundo, tornando o homem capaz de compreender e interpretar a história, fazendo com que ele se sinta parte dessa narração.

\title{
2.1 Tipos de biblioterapia
}

Visto que a biblioterapia está interligada a diversos campos de atuação profissional (Psicologia, Biblioteconomia, Medicina, Enfermagem entre outros), desta forma, Pereira (1996, apud SILVA, 2005, p. 17-18) descreve em "Biblioterapia: proposta de um programa de leitura para portadores de deficiência visual em Bibliotecas Públicas" que existem três aspectos no qual a biblioterapia pode ser divida, determinando a área de atuação de cada profissional para cada caso específico. São elas:

- Biblioterapia Institucional: refere-se ao uso de literatura - primeiramente didática com clientes, individualmente, e que já se encontra institucionalizada. O profissional indicado para atuar nesse tipo de biblioterapia são os bibliotecários juntamente com a supervisão de uma equipe médica, vale ressaltar que os pacientes indicados a esse tipo de terapia são as pessoas com problemas mentais. Atualmente esse tipo de biblioterapia não existe mais, ainda é possível encontrar projetos. (PEREIRA 1996, p. 57 apud SOUSA, 2012, p. 40).

De acordo com Valencia e Magalhães (2015, p. 12),

\begin{abstract}
A biblioterapia institucional é aplicada em grupo ou individual, por meio de uma equipe de profissionais aos pacientes. O objetivo é informar e esclarecer algum problema específico, ajudando no desenvolvimento pessoal, na tomada de decisão e reorientação de um comportamento conforme o objetivo definido para o trabaIho, fornecendo literatura sobre o assunto. Esta terapia pode ser aplicada por médicos, educadores, assistentes sociais e bibliotecários treinados dependendo do trabalho a ser desenvolvido.
\end{abstract}

- Biblioterapia Clínica: Segundo Sousa (2012, p. 41), “A biblioterapia clínica visa um auxílio a um grupo selecionado para o tratamento ou individualmente em determinada clínica ou hospital. Possui um enfoque em pessoas com problemas de saúde mental e distúrbio comportamental."

Valencia e Magalhães (2015) corroboram com ideia de que a biblioterapia clínica pode ser aplicada em hospitais, clinicas e instituições de apoio psicológico e psiquiátrico, tendo como objetivo trabalhar os problemas relacionados ao comportamento social, moral, emocional, físico entre outros, buscando auxiliar na mudança de comportamento e atitudes desses pacientes, visando diminuir ou até mesmo solucionar as dificuldades e problemas encontrados em cada caso. Para as autoras os profissionais mais indicados a exercer essa função são médicos, bibliotecários, terapeutas ocupacionais e psicoterapeutas, ou até mesmo por uma junção desses profissionais formando uma equipe multidisciplinar.

A biblioterapia no âmbito hospitalar na visão, Santos e Marquez (2017, p. 1591), dizem que: 
Dentro da Biblioteconomia, a biblioterapia é a prática responsável por utilizar o livro como intervenção terapêutica. Nessa vertente da profissão, o bibliotecário desempenha o papel de aplicador da biblioterapia, selecionando não apenas livros, mas todo tipo de textos que serão trabalhados como forma de leitura terapêutica, ou seja, a prescrição de materiais de leitura com função terapêutica que ajudem como instrumentos no restabelecimento psíquico de indivíduos com transtornos ou ainda em tratamento e convalescença.

- Biblioterapia de Desenvolvimento: De acordo com Sousa (2012, p. 41), a "Biblioterapia para desenvolvimento pessoal é indicada para programas educacionais voltados a crianças e adolescentes, podendo ser trabalhada de forma coletiva e possui um caráter preventivo e corretivo."

Conforme Valencia e Magalhães (2015, p. 12-13),

A biblioterapia de desenvolvimento pessoal é uma assistência literária personalizada que visa o desenvolvimento normal e progressivo do indivíduo que procurou por ajuda. Sua finalidade é auxiliar em tarefas comuns e a lidar com problemas do cotidiano, para o desenvolvimento pessoal, e tem o caráter preventivo e corretivo. É utilizada em instituições educacionais, para a identificação de futuras e possíveis fontes de problemas e é realizada por bibliotecários, educadores e assistentes sociais.

Caldin (2009) defende de que o material mais indicado para esse tipo de biblioterapia são os textos literários, pois eles possuem um poder terapêutico maiores do que o ficcional. Outro conceito defendido pela autora em sua tese é de que os melhores resultados obtidos na biblioterapia são aqueles realizados em grupo, pois a leitura solitária não permite uma troca de ideias.

Quadro 2 - Tipos de biblioterapia e suas características

\begin{tabular}{|c|c|c|c|}
\hline Categorias & Institucional & Clínica & Desenvolvimento \\
\hline Formato & $\begin{array}{l}\text { Individual ou grupo ge- } \\
\text { ralmente passivo. }\end{array}$ & $\begin{array}{l}\text { Grupo ativo voluntário e invo- } \\
\text { luntário. }\end{array}$ & $\begin{array}{l}\text { Grupo ativo, grupo volun- } \\
\text { tário. }\end{array}$ \\
\hline Cliente & $\begin{array}{l}\text { Paciente médico ou } \\
\text { psiquiátrico, prisioneiro } \\
\text { ou cliente em prática } \\
\text { privada. }\end{array}$ & $\begin{array}{l}\text { Pessoas com problemas emo- } \\
\text { cionais ou comportamentais. }\end{array}$ & $\begin{array}{l}\text { Pessoa normal geralmen- } \\
\text { te em situação de crise. }\end{array}$ \\
\hline Contratante & Sociedade. & Sociedade ou individual. & Individual. \\
\hline Terapêutica & $\begin{array}{l}\text { Equipe médica ou biblio- } \\
\text { tecária. }\end{array}$ & $\begin{array}{l}\text { Médico, instrutor de saúde } \\
\text { mental ou bibliotecário ge- } \\
\text { ralmente em consulta. }\end{array}$ & $\begin{array}{l}\text { Bibliotecário, professor ou } \\
\text { outros. }\end{array}$ \\
\hline Material usado & $\begin{array}{l}\text { Tradicionalmente didáti- } \\
\text { co. }\end{array}$ & Literatura Imaginativa. & $\begin{array}{l}\text { Literatura imaginativa } \\
\text { e/ou didática. }\end{array}$ \\
\hline Técnica & Discussão material. & $\begin{array}{l}\text { Discussão de material, com } \\
\text { ênfase nas visões e reações } \\
\text { do cliente. }\end{array}$ & $\begin{array}{l}\text { Discussão de material } \\
\text { com ênfase nas visões e } \\
\text { reações do cliente. }\end{array}$ \\
\hline Local & $\begin{array}{l}\text { Prática de instituição } \\
\text { pública ou privada. }\end{array}$ & $\begin{array}{l}\text { Prática de instituição privada } \\
\text { ou de comunidade. }\end{array}$ & Comunidade. \\
\hline Meta & $\begin{array}{l}\text { Geralmente informativo, } \\
\text { com alguma visão inter- } \\
\text { na. }\end{array}$ & $\begin{array}{l}\text { Visão interna e/ou mudança } \\
\text { de comportamento. }\end{array}$ & $\begin{array}{l}\text { Comportamento normal e } \\
\text { auto realização. }\end{array}$ \\
\hline
\end{tabular}

Fonte: Pereira (1996, p. 59, apud SOUSA, 2012, p. 42). 
A biblioterapia de desenvolvimento pessoal pode ser aplicada em todas as faixas etárias, sem distinção de gênero, seu objetivo principal é auxiliar no desenvolvimento pessoal do indivíduo, seja por meio de leituras em grupo, música, teatro, desenhos e entre outras atividades.

O Quadro 2 apresenta um panorama que contempla as características dos três tipos de biblioterapia.

\subsection{Método, técnica terapêutica e seus componentes}

O método biblioterapêutico conforme a definição de Caldin (2001, p.37) "[...] consiste em uma dinamização e ativação existencial por meio da dinamização e ativação da linguagem. As palavras não são neutras. A linguagem metafórica conduz o homem para além de si mesmo; ele se torna outro, livre no pensamento e na ação". A leitura é a responsável por despertar esse diálogo entre o grupo e a partir daí é que surgem os questionamentos, troca de ideias e experiências, momentos assim possibilitam que o indivíduo descubra o seu lado criativo e imaginário despertando suas emoções. Para Nascimento (2007, p. 9 apud VALENCIA; MAGALHÃES, 2015, p. 13), "[...] o diálogo pode ser uma fonte de restituição de vida em momentos de fragilidade angústia, desespero ou descrença".

\subsubsection{Técnicas terapêuticas}

De acordo com os autores, Ouakin (1996), Caldin (2001), Ribeiro (2006), Seitz (2006) e Nascimento (2007), conforme citado por Santos e Marquez (2017, p. 1592-1593), as técnicas biblioterapêuticas é outro ponto a ser discutido devido sua importância na aplicação da terapia por meio da leitura, sendo assim os autores Santos e Marquez (2017) apresentam de forma sintetizada os objetivos da técnica biblioterapêutica, são elas:
a) auxiliar na adaptação hospitalar;
b) diminuir a sensação de isolamento;
c) estimular novos interesses;
d) aliviar o estresse e as tensões diárias;
e) incitar o crescimento emocional;
f) ajudar a lidar com sentimentos de raiva e frustração;
g) perceber que seu problema já foi vivenciado por outras pessoas e que estes são universais, ajudar a libertar-se do medo;
h) diminuir a angústia, a tristeza e a solidão;
i) amenizar a depressão;
j) ajudar o paciente a conversar sobre seus problemas;
k) facilitar a socialização;
l) estimular a criatividade e a imaginação;
m) aumentar a auto estima;
n) proporcionar momentos de alegria e descontração;
o) incentivar o hábito pela leitura;
p) proporcionar uma atividade de lazer.

As autoras destacam a importância das técnicas biblioterapêuticas, pois através delas é possível despertar sentimentos bons, de prazer, descontração e bem-estar, amenizando por um determinado tempo os sentimentos ruins. 


\subsubsection{Componentes essenciais na aplicabilidade da biblioterapia}

Caldin (2001, p. 38-39) destaca 6 (seis) componentes fundamentais para que a biblioterapia seja executada com êxito:

- Catarse: a "catarse pode ser entendida como pacificação, serenidade e alívio das emoções".

- Humor: os textos que contém um toque de humor podem ser considerados bons instrumentos terapêuticos, a autora traz como apoio teórico.

Santos, Ramos e Sousa (2017) corroboram com a ideia de que o humor é um instrumento indispensável na otimização dos resultados biblioterapêuticos, pois ele proporciona ao indivíduo uma sensação de bem estar, criando uma barreira, ou seja, afastando de si os sentimentos ruins.

- Identificação: A identificação segundo a teoria freudiana tem seu inicio desde a construção da personalidade infantil, momento este que as crianças idealizam pessoas (pais, mães, amigo...) pelas elas se identificam e admiram.

Segundo o Vocabulário de Psicanálise, Laplanche e Pontalis (1994, p. 226, apud CALDIN, 2001, p. 38-39), a identificação é "um processo psicológico pelo qual um sujeito assimila um aspecto, uma propriedade, um atributo do outro e se transforma, total ou parcialmente, segundo o modelo desse outro".

- Introjeção: A introjeção constitui-se em um processo evidenciado pela investigação analítica: "o sujeito faz passar, de um modo fantasístico, de 'fora' para dentro', objetos e qualidades inerentes a esses objetos" (LAPLANCHE; PONTALIS, 1994, p. 248, apud CALDIN, 2001, p.39). Segundo a autora esse componente está estreitamente relacionada com a identificação.

- Projeção: Segundo Laplanche; Pontalis (1994, p. 374 apud CALDIN, 2001, p. 39), a projeção é, no sentido propriamente dito, operação pela qual o sujeito expulsa de si e localiza no outro - pessoa ou coisa - qualidades, sentimentos, desejos e mesmo 'objetos' que lê, desconhece, ou recusa nele. A projeção pode ser interpretada como uma forma de transferir para o outro nossas ideias, sentimentos e emoções.

- Introspecção: a introspecção está relacionada com a leitura terapêutica, pois é através do ato de ler que o indivíduo passa a refletir sobre seus sentimentos e emoções, permitindo uma mudança em seu comportamento e atitudes.

A introspecção, segundo Michaelis (1998, p. 699 apud CALDIN, 2001, p. 39), é a "descrição da experiência pessoal em termos de elementos e atitudes" a "observação, por uma determinada pessoa, de seus próprios processos mentais".

\subsection{A biblioterapia como campo de atuação para o bibliotecário}

Como já mencionado ao decorrer da pesquisa com base nos autores consultados, a biblioterapia abrange um campo de atuação muito amplo, tornando-se assim uma área multidisciplinar, autores como Caldin (2001, 2009), Ferreira (2003) e Pinto (2005) defendem a ideia de que a biblioterapia é uma possível área de atuação para o bibliotecário, desde que este esteja capacitado e/ou acompanhado por outros profissionais, psicólogos ou terapeutas.

A contribuição do bibliotecário nas atividades biblioterapêuticas pode ocorrer de diversas formas, sejam por meio da dramatização de histórias, atividades lúdicas entre outras 
funções, pois este profissional dispõe de um papel social no qual é de grande ajuda para compreender o próximo, desempenhando o seu lado humanístico, auxiliando desde a seleção do material até a aplicação da atividade. O Quadro 3, apresenta alguns autores e sua visão sobre a atuação do bibliotecário na biblioterapia.

Quadro 3 - Visão sobre a atuação do bibliotecário na biblioterapia

\begin{tabular}{|c|l|}
\hline Autor & \multicolumn{1}{|c|}{ Defende a ideia } \\
\hline Pereira (1996) & $\begin{array}{l}\text { Defende o bibliotecário como biblioterapêuta, porém, este atuaria em conjunto com } \\
\text { outros profissionais, sendo de seu encargo lidar com os livros no que diz respeito à } \\
\text { seleção, aquisição, manutenção e distribuição, além de avaliação da atividade. }\end{array}$ \\
\hline Hanningan (1962) & $\begin{array}{l}\text { Compara o bibliotecário a um farmacêutico, pois disponibiliza os livros prescritos, } \\
\text { podendo sugerir tanto leituras como a atividade com o paciente. }\end{array}$ \\
\hline Pinto (2005) & $\begin{array}{l}\text { A biblioterapia é uma seara de atuação para o bibliotecário, porém a sua prática ne- } \\
\text { cessita de conhecimentos do terreno da psicoterapia; portanto essa vivência deveria } \\
\text { ser implementada conjuntamente com psicólogos, terapeutas e outros profissionais } \\
\text { desse ramo. }\end{array}$ \\
\hline Hasse (2004) & $\begin{array}{l}\text { Afirma que o bibliotecário é inapto para aplicar tal atividade, pois necessita de uma } \\
\text { capacitação diferente do que o curso exige do futuro profissional. }\end{array}$ \\
\hline Caldin (2010) & $\begin{array}{l}\text { Afirma que para o bibliotecário que busca aplicar tal atividade, é necessário ter um } \\
\text { perfil social de profissional, e inclusive ter uma estrutura emocional, física e moral } \\
\text { estável, e ressalta que esse bibliotecário está apto para ser aplicador da Biblioterapia, } \\
\text { não para ser biblioterapêuta. }\end{array}$ \\
\hline Sousa (2012) & $\begin{array}{l}\text { A biblioterapia é um ótimo campo profissional para o bibliotecário. Este profissional } \\
\text { pode buscar competências para aplicar projetos, além de buscar parcerias com profis- } \\
\text { sionais de outras áreas. }\end{array}$ \\
\hline
\end{tabular}

Fonte: Adaptado de Guedes e Baptista (2013, p. 245).

Na visão de Ferreira (2003) a função do bibliotecário junto às atividades de biblioterapia é definida pela sua formação e interação com os demais profissionais, pelo planejamento e aplicação do projeto, e os objetivos almejados. O autor ainda descreve algumas diretrizes a ser seguidas não só pelos bibliotecários, mas pelos profissionais atuantes nas atividades biblioterapêuticas.

a) Ele deve escolher um local adequado para a realização das reuniões do grupo;

b) Deve ter tido um treinamento adequado e estar capacitado para conduzir as discussões do grupo;

c) Deve formar grupos homogêneos para leitura e discussão de temas previamente escolhidos;

d) Deve preparar listas de material bibliográfico adequadas às necessidades de cada grupo, e escolher outros materiais (filmes, músicas), de acordo com a idade e necessidades a nível cultural e social dos participantes;

e) Mesmo que não haja aplicação de terapia ou psicoterapia, como em alguns casos de biblioterapia para crianças, é necessário estabelecer uma situação de ajuda entre o bibliotecário e o usuário, a partir daí será possível elaborar um programa estruturado;

f) O bibliotecário ou biblioterapêuta deve usar de preferência materiais com os quais esteja familiarizado; 
g) Deve selecionar materiais que contenham situações familiares aos participantes do grupo, mas que não precisam necessariamente conter situações idênticas às vividas pelas pessoas envolvidas no processo;

h) Deve selecionar materiais que traduzam de forma precisa os sentimentos e os pensamentos das pessoas envolvidas sobre os assuntos e temas abordados, com exceção de materiais que contenham uma conotação muito negativa do problema, como poesias sobre suicídios, por exemplo;

i) Deve selecionar materiais que estejam de acordo com a idade cronológica e emocional da pessoa, sua capacidade individual de leitura e suas preferências culturais e individuais e;

j) Deve selecionar material impresso e não impresso na mesma medida. (FERREIRA, 2003, p.43).

As diretrizes servem como suporte/orientação para que os projetos sejam organizados e aplicados de forma eficaz, visando a otimização dos resultados, Caldin (2001, p. 42) corrobora que "Vale destacar que não é a designação o mais importante na atividade de terapia da leitura, mas, o resultado obtido".

As terapias por meio da leitura exigem dos profissionais bibliotecários uma capacitação que vai além da graduação. De acordo com Conselho Regional de Biblioteconomia-8 (2018), os bibliotecários atuantes nas atividades biblioterapêuticas carecem de uma especialização, seja por meio da leitura sobre o tema em questão, através de visitas a sites sobre a biblioterapia ou até mesmo através de cursos e palestras.

Nessa busca, foram encontrados 14 itens com o tema, tanto no título como no assunto. Destes 14 itens, são: duas teses e 12 dissertações conforme a Biblioteca Digital Brasileira de Teses e Dissertações do Instituto Brasileiro de Informação em Ciência e Tecnologia (BDTD/IBICT).

Desses 14 itens recuperados foram analisados apenas sete documentos, sendo eles da área de Biblioteconomia, Ciência da Informação e Gestão da Informação, os demais pertencem a outras áreas.

Como indagação do segundo objetivo, a pesquisa realizada no Portal do Ministério da Educação (MEC) e Associação Brasileira de Educação em Ciência da Informação ( $A B E C I N)$ obteve como resposta 36 universidades brasileiras entre pública e privada que possuem o curso de Biblioteconomia no Brasil.

A terceira etapa faz uma abordagem sobre os resultados obtidos na etapa anterior, realizando uma breve análise sobre a bibliografia recuperada na base BDTD e um levantamento das universidades que oferecem a disciplina de biblioterapia como forma de agregar conhecimento aos formandos em Biblioteconomia.

Por sua vez, a quarta e última etapa permitem a autora fazer uma reflexão sobre o contexto do assunto abordado, os dados recuperados, expondo seu ponto de vista.

No presente trabalho optou-se como universo da pesquisa a base de dados BDTD do IBICT, fazendo um levantamento sobre as teses e dissertações publicadas na área de Biblioteconomia e Ciência da Informação que abordam a temática "biblioterapia". Buscou-se também saber quais as universidades brasileiras possuem o curso de Biblioteconomia e nos seus respectivos QSL quais as que ofertavam a disciplina Biblioterapia.

\section{RESULTADOS E DISCUSSÕES}

Em busca de respostas para o primeiro objetivo específico desse trabalho, analisaram-se sete dos quatorzes documentos (teses e dissertações) encontrados na base de dados 
da BDTD/IBICT, a partir do ano de 2000, visando identificar nestas bibliografias, os enfoques dados à biblioterapia, através dos trabalhos científicos realizados por pesquisadores da área de Biblioteconomia e da Ciência da Informação. Dessa forma, demonstra-se no quadro 4, as obras recuperadas e analisadas em ordem cronológica:

Quadro 4 - Dissertações e Teses com o tema Biblioterapia

\begin{tabular}{|c|l|l|c|c|}
\hline No & \multicolumn{1}{|c|}{ Autor } & \multicolumn{1}{|c|}{ Título } & Ano & Área/documento \\
\hline 01 & Seitz, Eva Maria & $\begin{array}{l}\text { Biblioterapia: uma experiên- } \\
\text { cia com pacientes internados } \\
\text { em clinica médica }\end{array}$ & 2000 & Biblioteconomia/Dissertação \\
\hline 02 & $\begin{array}{l}\text { Silva, Alexandre Mag- } \\
\text { no da }\end{array}$ & $\begin{array}{l}\text { Características da produção } \\
\text { documental sobre bibliotera- } \\
\text { pia no Brasil }\end{array}$ & 2005 & Biblioteconomia/Dissertação \\
\hline 03 & $\begin{array}{l}\text { Miranda, Maria Rosa } \\
\text { Pimentel Faria de }\end{array}$ & $\begin{array}{l}\text { Informação, leitura e inclusão } \\
\text { educacional e social nas bi- } \\
\text { bliotecas braille de Campo } \\
\text { Grande/MS: um estudo de } \\
\text { caso }\end{array}$ & 2006 & Ciência da Informação/Dissertação \\
\hline 05 & $\begin{array}{l}\text { Guedes, Mariana } \\
\text { Giubertti }\end{array}$ & $\begin{array}{l}\text { A biblioterapia na realidade } \\
\text { diação da informação }\end{array}$ & 2013 & Biblioteconomia/Dissertação \\
\hline 06 & Silva, Carla Sousa da & $\begin{array}{l}\text { Biblioterapia no Brasil e na } \\
\text { Polônia }\end{array}$ & 2017 & Biblioteconomia/Dissertação \\
\hline Limagas, Ricardo de & $\begin{array}{l}\text { Rede de bibliotecas em am- } \\
\text { bientes de saúde mental }\end{array}$ & 2017 & Gestão da informação/Dissertação \\
\hline
\end{tabular}

Fonte: Portal do IBICT (2018).

Com base nos documentos consultados constatou-se que a biblioterapia vem sendo explorado nos mais variados campo de atuação profissional, inclusive na área de Biblioteconomia. Os bibliotecários têm despertado crescentemente o interesse por esse assunto, seja na área da pesquisa como também na participação das atividades biblioterapêuticas, desse modo podemos dizer que a biblioterapia pode sim ser aplicada por um profissional da área de Biblioteconomia, desde que esse possua uma preparação para lidar com diversos tipos de situações que podem ocorrer. Pois a terapia através dos livros não se limita uma única contação de história ou até mesmo uma roda de leitura, ela vai além do ato de ler. É criar a necessidade de um diálogo dirigido para que a discussão ocorra de forma que o ouvinte/leitor desperte o seu mundo imaginário e sinta-se parte dessa narração, expondo suas dificuldades e agregando para si sentimentos e emoções que minimizem os sentimentos de frustração, angústia, medo, depressão sensações ruins que fazem parte do seu dia-a-dia. Até mesmo o desconforto causado pela internação hospitalar tanto ao paciente quanto ao acompanhante.

De acordo com Miranda (2006), o bibliotecário surge como um arquiteto da informação e mediador da inclusão social e educacional através de suas habilidades de leitura. Por sua vez, Guedes (2013), destaca que existem poucos profissionais aptos a exercer a biblioterapia. Segundo Garcia (2014), em uma pesquisa realizada com os discentes do curso de Biblioteconomia das Universidades Federal e Estadual de Santa Catarina (UFSC) e a Universi- 
dade do Estado de Santa Catarina (UDESC), observou-se que os discentes possuem certo conhecimento e interesse por essa área, talvez porque a disciplina de biblioterapia faz parte do QSL do curso.

\begin{abstract}
Também consideram que a Biblioterapia deve ser mais aplicada e explorada nos cursos de Graduação em Biblioteconomia, por se tratar de uma ferramenta mediadora com função integradora (bibliotecário x sociedade e bibliotecário x outros profissionais), além das possibilidades de realçar o lado humano do profissional bibliotecário. (GARCIA, 2014, p. 106).
\end{abstract}

A biblioterapia vem se destacando como alternativa para diversos tipos de tratamento, tanto na área social quanto na emocional, por se tratar de um campo multidisciplinar o bibliotecário pode ser inserido como um mediador da informação desenvolvendo seus conhecimentos e técnicas aliado a outros profissionais. O profissional apto a exerce as atividades biblioterapêuticas carecem de uma preparação agregando maiores conhecimentos sobre o tema, Garcia (2014) traz como exemplo de complementação na área da biblioteconomia a UFSC, a pioneira das universidades a ofertarem a disciplina no curso de Bacharel em Biblioteconomia, sendo que todos os alunos de graduação da universidade podem optar em cursá-la, a autora corrobora com a ideia de que,

\footnotetext{
O interesse pela Biblioterapia como prática de atuação do profissional bibliotecário que sendo inserida no contexto de formação, ou seja, nos cursos de Biblioteconomia, enquanto disciplina curricular ajuda na sua ampliação e fortalecimento enquanto campo de atuação do bibliotecário, bem como, a entender o aspecto humano da profissão. (GARCIA, 2014, p. 58).
}

Deste modo, surgiu à curiosidade em conhecer as universidades que possuem o curso de Biblioteconomia, identificando quais dessas ofertam a Biblioterapia como disciplina nos QSL dos cursos.

Foram analisadas 36 universidades brasileiras entre pública e privada no qual o curso de Biblioteconomia faz parte da sua grade curricular, visando identificar quais dessas instituições aderiram à disciplina de Biblioterapia como forma de ampliar os conhecimentos dos discentes, sendo que a área biblioterapêutica tem se mostrado mais uma alternativa de atuação para os bibliotecários.

Foi realizada uma busca no site de cada universidade visando analisar os QSL dos cursos de Biblioteconomia, de forma a ser respondido o segundo objetivo específico desse trabalho, ao término dessa consulta constatou-se que das 36 universidades apenas uma das instituições, a Universidade Federal de Santa Catarina (UFSC), implantou em sua grade curricular a disciplina de biblioterapia, como optativa. Disponibilizando, assim, aos discentes de todos os cursos de graduação da universidade.

\title{
4 CONSIDERAÇÕES FINAIS
}

Por meio da literatura científica comprovou-se que a biblioterapia é uma atividade muito importante, analisando através de algumas experiências realizadas com resultados positivos. A terapia por meio da leitura é vista como um grande aliado a inúmeros tratamentos inclusive hospitalares e de restabelecimento pessoal.

Observou-se que não existe uma única área de conhecimento responsável pela biblioterapia, esta por sua vez, trata-se de uma atividade multidisciplinar profissionais de dife- 
rentes campos de atuação, na qual, podem trabalhar em conjunto ou individualmente, o que vai determinar o tipo de profissional a desenvolver essa atividade terapêutica. O bibliotecário é um dos profissionais que pode trabalhar com a biblioterapia devido a sua facilidade de leitura e interpretação como um mediador da leitura.

De todas as instituições analisadas, apenas uma oportuniza aos seus discentes um maior conhecimento e domínio sobre o tema em questão. O resultado obtido nessa busca foi frustrante, pois se a biblioterapia é um campo de atuação para os bibliotecários comprovado por pesquisadores como Caldin (2001), Miranda (2006), Guedes (2013), Garcia (2014) entre outros que foram abordados ao decorrer desse estudo.

Os cursos oferecem uma carga horária de matérias optativas a ser cumprida até a conclusão da graduação e as instituições de ensino ofertam cadeiras voltadas à leitura, contação de histórias, pesquisas, bibliotecas escolares e alternativas. Portando, permitir aos alunos a opção agregar conhecimentos através de uma disciplina voltada para o lado social. A biblioterapia não se resume ao ato de ler, mas sim desempenhar um papel social perante a comunidade, ter empatia e amor ao próximo.

A partir dessas discussões entende-se a escassez do bibliotecário atuante nas atividades biblioterapêuticas, pois se há uma carência na formação e capacitação desse profissional logo não encontraremos pessoas capacitadas suficiente para atuar na área da biblioterapia.

Para finalizar, sugere-se que outros pesquisadores identifiquem quais os motivos dos Cursos de Biblioteconomia não ofertarem a disciplina "biblioterapia" em seu Quadro de Sequência Lógica (QSL). Já que é tão importante na "[...] sua ampliação e fortalecimento enquanto campo de atuação do bibliotecário, bem como, a entender o aspecto humano da profissão." (GARCIA, 2014, p. 58).

\section{REFERÊNCIAS}

ASSOCIAÇÃO BRASILEIRA DE EDUCAÇÃO EM CIÊNCIA DA INFORMAÇÃO (ABECIN). Cursos. Sergipe: ABECIN, c2016. Disponível em: http://www.abecin.org.br/cursos. Acesso em: 28 abr. 2018.

CALDIN, C. F. A leitura como função terapeutica: biblioterapia. Enc. Bibli: R. Eletr. Bibliotecon. Ci. Inf., Florianópolis, n. 12, p. 32-44, 2001. Disponível em: https://periodicos.ufsc.br/index.php/eb/article/view/1518-2924.2001v6n12p32/5200. Acesso em: 25 abr 2018.

CALDIN, C. F. Leitura e terapia. 2009.Tese (Doutorado em Literatura) - Universidade Federal de Santa Catarina, Centro de Comunicação e Expressão. Programa de Pós-graduação em Literatura, Florianópolis, 2009. Disponível em:

https://repositorio.ufsc.br/handle/123456789/92575. Acesso em: 02 maio 2018.

CONSELHO REGIONAL DE BIBLIOTECONOMIA 8 (CRB8). 3 passos simples para trabalhar com biblioterapia. São Paulo: CRB8, 2018. Disponível em: http://www.crb8.org.br/3-passos-simplespara-trabalhar-com-biblioterapia/. Acesso em: 18 jun. 2018. 
FERREIRA, D. T. Biblioterapia: uma prática para o desenvolvimento pessoal. Educação Temática Digital, Campinas, São Paulo, v. 4, n. 2, p. 35-47, jun. 2003. Disponível em: https://periodicos.sbu.unicamp.br/ojs/index.php/etd/article/view/620. Acesso em: 07 jun. 2018.

GARCIA, I. H. Biblioterapia: percepções dos discentes dos cursos de biblioteconomia das Universidades Federal e Estadual de Santa Catarina. 2014. Dissertação (Mestrado em Ciência da Informação) - Universidade Federal de Santa Catarina, Centro de Ciências da Educação, Programa de Pós-Graduação em Ciência da Informação, Florianópolis, 2014. Disponível em: https://repositorio.ufsc.br/handle/123456789/132443. Acesso em: 20 dez. 2019.

GUEDES, M. G. A biblioterapia na realidade bibliotecária no Brasil: a mediação da informação. 2013. Dissertação (Mestrado em Ciência da Informação) - Universidade de Brasília, Faculdade de Ciência da Informação, Programa de Pós-Graduação em Ciência da Informação, Brasília, 2013. Disponível em:

http://repositorio.unb.br/bitstream/10482/13659/1/2013 MarianaGiuberttiGuedes.pdf. Acesso em: 08 jun. 2018.

GUEDES, M. G.; BAPTISTA, S. G. Biblioterapia na ciência da informação: comunicação e mediação. Enc. Bibli: R. Eletr. Bibliotecon. Ci. Inf., Florianópolis, v. 18, n. 36, p. 231-253, 2013. Disponível em: https://periodicos.ufsc.br/index.php/eb/article/view/1518-

2924.2013v18n36p231/24527. Acesso em: 07 jun. 2018.

MIRANDA, M. R. P. F. Informação, leitura e inclusão educacional e social nas bibliotecas braille de Campo Grande/MS: um estudo de caso. 2006. Dissertação (Mestrado em Ciência da Informação) - Universidade de Brasília, Faculdade de Ciência da Informação, Programa de Pós-Graduação Interinstitucional em Ciência da Informação - UnB/UNIDERP, Brasília, 2006. Disponível em: https://repositorio.unb.br/handle/10482/1881. Acesso em: 23 out. 2018.

PINTO, V. B. A biblioterapia como campo de atuação para o bibliotecário. Transinformação, Campinas, São Paulo, v. 17, n. 1, p. 31-43, jan./abr., 2005. Disponível em:

http://periodicos.puc-campinas.edu.br/seer/index.php/transinfo/article/view/703/683.

Acesso em: 07 jun. 2018.

ROSA, A. L. R. As cartas de Ana Cristina César: uma contribuição para a biblioterapia. 2006. Dissertação (Mestrado em Letras) - Universidade do Vale do Rio Verde UNINCOR, Três Corações, Minas Gerais, 2006. Disponível em:

http://www.unincor.br/images/imagens/2017/mestrado letras/APARECIDA LUCIENE RESENDE RO SA.pdf. Acesso em: 31 maio 2018.

SANTOS, A. P.; RAMOS, R. B. T.; SOUSA, T. C. S. Biblioterapia: estudo comparativo das práticas biblioterápicas brasileiras e norteamericanas. Rev. Eletron. Comum. Inf. Inov. Saúde, v. 11, n.2, abr./jun., p.1 -15, 2017. Disponível em:

https://www.reciis.icict.fiocruz.br/index.php/reciis/article/view/1072/2119. Acesso em: 06 ago. 2018.

SANTOS, M. A.; MARQUEZ, S. O. M. Biblioterapia: a contribuição da biblioterapia no tratamento de pacientes internado em unidades hospitalar. Revista Brasileira de Bibliotecono- 
mia e Documentação, São Paulo, v. 13, n. Esp. CBBD 2017, p. 1588-1609, 2017. Disponível em: https://febab.emnuvens.com.br/rbbd/article/view/774/897. Acesso em: 01 jun. 2018.

SILVA, A. M. Características da produção documental sobre biblioterapia no Brasil. 2005. Dissertação (Mestrado em Psicologia) - Universidade Federal de Santa Catarina, Centro de Filosofia e Ciências Humanas, Programa de Pós-Graduação em Psicologia, Florianópolis, 2005. Disponível em:

https://repositorio.ufsc.br/bitstream/handle/123456789/101729/220699.pdf?sequence=1\&isAllowe $\mathrm{d}=\mathrm{y}$. Acesso em: 29 maio 2018.

SILVA, C. S. Biblioterapia no Brasil e na Polônia: distâncias e aproximações a partir da literatura científica. 2017. Dissertação (Mestrado em Ciência da Informação) - Universidade Federal de Santa Catarina, Centro de Ciências da Educação, Programa de Pós-Graduação em Ciência da Informação, Florianópolis, 2017. Disponível em: https://repositorio.ufsc.br/handle/123456789/179007. Acesso em: 01 jun. 2018.

SOUSA, T. C. S. Biblioterapia: estudo de revisão e comparativo da produção brasileira e norte americana. Trabalho de Conclusão de Curso (Bacharel em Biblioteconomia) Universidade de Goias, Faculdade de Comunicação e Biblioteconomia. Goiânia, 2012. Disponível em: https://repositorio.bc.ufg.br/bitstream/ri/4289/2/TCCG-BIBLIOTECONOMIATHAIS\%20SOUSA.pdf. Acesso em: 28 maio 2018.

VALENCIA, M.; MAGALHÃES, M. C. Biblioterapia: síntese das modalidades terapêuticas utilizadas pelo profissional. Biblos: Revista do Instituto de Ciências Humanas e da Informação, v. 29, n. 1, p. 5-27, 2015. Disponível em: https://periodicos.furg.br/biblos/article/view/4585/3533. Acesso em: 07 jun. 2018 